\title{
Real-world observational study of the evaluation of inhaler techniques in asthma patients
}

\author{
Chaicharn Pothirat, Warawut Chaiwong, Atikun Limsukon, Nittaya Phetsuk, Nonglak Chetsadaphan, \\ Woranoot Choomuang, Chalerm Liwsrisakun
}

\begin{abstract}
Background: Inhaler devices are a keystone in the management of asthma during the maintenance phase of treatment.

Objective: To evaluate techniques for using inhaler devices in asthma patients.

Methods: A prospective cross-sectional study was conducted to assess patient compliance with correct techniques for using inhaler devices across three regimens: pressurized metered-dose inhaler (pMDI), Accuhaler ${ }^{\circledast}$, and Turbuhaler ${ }^{\odot}$. The compliance of patients with essential steps for correct device usage in the case of each regimen was recorded. These were recorded when patients presented for a routine visit and one month after receiving face-to-face training. The percentage of compliance between the use of the devices and the risk factors related to incorrect techniques were analyzed by logistic regression analysis. The percentages of incorrect techniques were compared between the two visits using a Chi-squared test.
\end{abstract}

Results: A total of 108 asthma patients (35.2\% male), with a mean age of $57.5 \pm 12.3$ years were evaluated. Percentages of incorrect use of Accuhaler ${ }^{\oplus}$, pMDI, and Turbuhaler ${ }^{\circledast}$ were $50 \%, 48 \%$, and $55.6 \%$, respectively. The most common incorrectness's is breath out gently to residual volume (approximately one-third). Previous treatment by a pulmonologist for less than 2 years was the single factor related to incorrect technique [Adjusted $\mathrm{OR}=2.8(95 \% \mathrm{CI}, 1.2-6.3), p=0.02$ ] Formal training resulted in a statistically significant decrease in percentage of incorrect techniques $(52.8 \%$ vs. $32.1 \%, p$ $=0.02)$.

Conclusion: Inhalation technique in asthma patients was mostly unsatisfactory, especially in patients who had been treated by a pulmonologist for less than 2 years. Face-to-face training significantly improved good technique in all devices.

Key words: asthma, inhalation, technique, device, medication

\section{From:}

Division of Pulmonary, Critical Care and Allergy, Department of Internal Medicine, Faculty of Medicine, Chiang Mai University, Chiang Mai, Thailand.

\section{Introduction}

Inhaler devices are a keystone in the management of asthma during the maintenance phase of treatment, ${ }^{1}$ and the proper use for effective therapy requires continuous training. ${ }^{2}$ However, the study about management of asthma in Thailand showed a large proportion of asthmatic patients have inappropriate concepts about asthma treatment especially for inhaler controllers. ${ }^{3}$

Device selection should be based on availability, cost, patient and physician preference, and the clinical setting.,
Corresponding author:

Chaicharn Pothirat

110 Inthavaroros Rd. Sriphum, Maung Chiang Mai, Chiang Mai, 50200 Thailand

E-mail: chaicharn.p@cmu.ac.th

Many inhaler devices have been developed and each one has specificities on preparation for provision of a suitable dose, and drug delivery to the airways. Although the different devices have had many technological improvements over the years in airway drug delivery, important limitations still remain. ${ }^{6}$

Poor inhalation techniques are associated with decreased medication delivery and poor disease control. ${ }^{7}$ The correct use of inhaler devices is one of the most important aspects to be 
taken into account when evaluating the progress of disease treatment among individuals with asthma, and guidelines emphasize the importance of assessing inhalation techniques to improve the efficiency of drug delivery. ${ }^{8}$ Previous studies have reported errors in the use of such inhaler devices. ${ }^{1,9,10}$ In several previous studies about incorrect technique used in asthma, failure at some point to use the device most effectively was reported in up to $94 \%$ of patients. ${ }^{1,9-11}$ Patient-related determinants such as sex, ${ }^{9}$ age, ${ }^{12,13}$ and educational level, ${ }^{12}$ were associated with incorrect technique. The type of inhaler device is also an important determinant as regards incorrect technique. ${ }^{12,14}$ Therefore, it is essential for the physicians, nurses, and other health care providers, to understand the issues related to the performance and correct use of these inhaler devices, and also to understand the difficulties faced by patients while using them. In Thailand, information regarding the use of inhalers is very limited; to date only two pertinent studies have been conducted and those were in children with asthma and chronic obstructive pulmonary disease (COPD). ${ }^{15,16}$ Therefore, the objective of this study was to evaluate and analyze inhalation techniques in asthma patients using common devices in real life practice.

\section{Methods}

A prospective cross-sectional study was conducted at the outpatient chest clinic of Maharaj Nakorn Chiang Mai Hospital, Chiang Mai, Thailand from December 2014 to November 2016. We assessed commonly used controller devices available in Thailand including the pressurized metered-dose inhaler (pMDI), Accuhaler ${ }^{\circledast}$, and Turbuhaler ${ }^{\circledast}$ Asthma patients whose condition is stable, had been previously diagnosed in accordance with the Global Strategy for Asthma Management and Prevention, Global Initiative for Asthma (GINA) ${ }^{7}$ and who had been using one of three types of inhaler devices for 3 months or longer prior to the study were included in this study. Patients using other kinds of inhaler device and having acute exacerbation or hospitalization within the past 6 weeks were excluded. Enrolled patients were assessed for inhalation technique at their routine medical visits (pre-training visits) without prior notification by a qualified respiratory nurse. This assessment was carried out in an infirmary room prior to meeting their physicians. The use of each inhaler device was evaluated in a practical manner, by asking patients to demonstrate their inhalation techniques using their prescribed devices containing placebo medications. They were asked to actually perform their usual technique so that all of the steps could be clearly observed. We developed a checklist to record all essential steps required for adequate drug delivery for each device based on the instructions provided by the manufacturer. The number of required steps varied from 6 to 7 depending on the device (Appendix 1). When one or more errors were made with regard to these essential steps, we considered it unlikely that sufficient medication would be inhaled. In these cases inhalation technique was defined as incorrect. The respiratory nurse observed each step of the inhalation technique and recorded each incorrect step. After the assessment patients were given instructions, face-to-face demonstrations regarding the correct use of the controller devices, and training until they could use the devices correctly. One month later (post-training visits), all patients were requested to demonstrate their inhalation techniques and they were re-evaluated by the same nurse.

All subjects underwent spirometry in accordance with guidelines of the American Thoracic Society (ATS) and the European Respiratory Society (ERS) ${ }^{17}$ to measure forced expiratory volume in the first second $\left(\mathrm{FEV}_{1}\right)$, and forced vital capacity (FVC). The ratio of $\mathrm{FEV}_{1}$ to FVC was calculated $\left(\% \mathrm{FEV}_{1} / \mathrm{FVC}\right)$. This was repeated with all patients unless their medical records contained documented results of spirometry within the past 6 months. The Thai version of the asthma control test (ACT) was administered to all subjects at the enrollment visit and follow-up visit. ${ }^{18}$ The types of inhaler controller device were also recorded. Any exacerbation of condition within the previous year was also noted. Exacerbation was defined as representing a change in symptoms and lung function from the patient's usual status according to GINA guideline. ${ }^{8,19}$

Patients were evaluated for potential risk factors associated with incorrect inhalation technique including age, sex, lung function (\% predicted of $\mathrm{FEV}_{1} \geq 70$ was defined as mild severity of obstruction and ratio of $\mathrm{FEV}_{1} / \mathrm{FVC}(\%)<70$ was defined as fixed airway obstruction according to the ATS/ERS 2005 guidelines), ${ }^{20}$ level of asthma control assessed by ACT (an ACT score $\geq 20$ was determined as well controlled asthma), ${ }^{21}$ level of education (low education level was defined as education $\leq 6$ years), ${ }^{16}$ and duration of treatment with pulmonologist. All factors were recorded. The study was approved by the Research Ethics Committee of the Faculty of Medicine, Chiang Mai University (Study code: MED-2557-02630, Date of approval: $12^{\text {th }}$ November 2014).Written informed consent was obtained from each patient prior to the study.

\section{Statistical analysis}

Data are presented as mean \pm standard deviation (SD) unless stated otherwise. Handling errors per device were defined as the percentage of subjects who incorrectly performed any step. The relationship between type of device and incorrect inhalation technique were analyzed using multivariable logistic regression and the Accuhaler ${ }^{\oplus}$ was set as reference. The potential risk factors of an incorrect inhalation technique from univariable logistic regression analysis with a $p$-value $<0.25$ were further analyzed using multivariable logistic analysis. ${ }^{22}$ Results are displayed as odds ratios (OR) together with 95\% confidence intervals (CI). Comparison percentages of incorrect inhalation technique between pre and post-training visits within groups were analyzed using a Chi-squared test. Comparison of clinical control by means of ACT score between routine visit and one month after reinforcement of the correct use of controller devices were analyzed using a paired t-test. Statistical significance was accepted at $p$-value $<0.05$. All analyses were carried out using the SPSS statistical package, version 22 for IBM; Chicago, IL.

\section{Results}

A total of 108 asthma patients were included in this study. Patient demographics and clinical characteristics are presented in Table 1. The mean age of the group was $57.5 \pm 12.3$ years old, predominantly female (64.8\%), with $74.2 \pm 20.2 \%$ predicted of $\mathrm{FEV}_{1}$. Most of them had a high education level 
(secondary school or higher), and slightly more than half of them had been receiving treatment from a pulmonologist at our chest clinic for at least 2 years.

Accuhaler $^{\circledast}$ users $(\mathrm{n}=75,69.4 \%)$ were the highest among the enrolled population followed by Turbuhaler ${ }^{\oplus}$ (n $=19,17.6 \%)$, and pMDI $(\mathrm{n}=14,13.0 \%)$. Fifty-three patients (49.1\%) performed at least one essential step incorrectly for all devices. For the analysis per device, percentages of incorrect essential steps and univariable analysis of performance of an incorrect technique per device are presented in Table 2. The highest number of technique errors was observed in those using the Turbuhaler ${ }^{\circledast}(55.6 \%)$, and the lowest in those using the Accuhaler ${ }^{\circledast}$ (48.0\%). In the case of the pMDI the steps "breathe out gently to residual volume" and "shake inhaler thoroughly" were most frequently performed incorrectly. In the Accuhaler the steps "breathe out gently to residual volume" and "inhale forcefully and deeply" were most

Table 1. Demographic and clinical characteristics of asthma patients in the study

\begin{tabular}{|c|c|}
\hline Characteristics & $\mathrm{n}=108$ \\
\hline Age (years) & $57.5 \pm 12.3$ \\
\hline Female sex, n (\%) & $70(64.8)$ \\
\hline Body mass index $\left(\mathrm{kg} / \mathrm{m}^{2}\right)$ & $24.3 \pm 4.2$ \\
\hline \multicolumn{2}{|l|}{ Education level } \\
\hline Low education ( $\leq 6$ years) & $29(26.9)$ \\
\hline High education ( $>6$ years) & $79(73.1)$ \\
\hline$\%$ predicted of $\mathrm{FEV}_{1}{ }^{\mathrm{a}}$ & $74.2 \pm 20.2$ \\
\hline Ratio of $\mathrm{FEV}_{1} / \mathrm{FVC}(\%)^{\mathrm{a}}$ & $73.2 \pm 10.3$ \\
\hline ACT score & $21.2 \pm 3.8$ \\
\hline History of AE in the previous year & $29(26.9)$ \\
\hline No. of $\mathrm{AE}$ in the previous year & $0.4 \pm 0.9$ \\
\hline Treated by a pulmonologist for at least 2 years & $69(63.9)$ \\
\hline
\end{tabular}

Notes: Data are $\mathrm{n}(\%)$ or mean $\pm \mathrm{SD},{ }^{\mathrm{a}} \mathrm{n}=92$

Abbreviations: $\mathrm{FEV}$, forced expiratory volume in first second;

FVC, forced vital capacity; ACT, Asthma control test; AE, acute exacerbation frequently performed incorrectly. In the Turbuhaler ${ }^{\circledast}$ the step "breathe out gently to residual volume" was most frequently performed incorrectly. Multivariable analysis (Accuhaler ${ }^{\oplus}$ device set as a reference group due to the lowest incorrect steps of inhalation) revealed insignificant differences in incorrect inhalation techniques between devices as demonstrated by the odds ratios presented in Table 2 .

Table 2. Percentages of mistakes per step, total percentages of patients with incorrect inhalation techniques per controller device, and univariate analysis per device

\begin{tabular}{|c|c|c|c|}
\hline Essential steps & $\begin{array}{l}\text { pMDI } \\
\mathrm{n}=14\end{array}$ & $\begin{array}{l}\text { Accuhaler }^{\oplus} \\
\mathbf{n}=75\end{array}$ & $\begin{array}{c}\text { Turbuhaler }^{\oplus} \\
\mathrm{n}=19\end{array}$ \\
\hline Shake inhaler thoroughly & 35.7 & $\mathrm{n} / \mathrm{a}$ & $\mathrm{n} / \mathrm{a}$ \\
\hline $\begin{array}{l}\text { Remove the cap and keep } \\
\text { inhaler in upright position }\end{array}$ & 0.0 & $\mathrm{n} / \mathrm{a}$ & 0.0 \\
\hline $\begin{array}{l}\text { Slide the outer case away until } \\
\text { it clicks }\end{array}$ & $\mathrm{n} / \mathrm{a}$ & 4.0 & $\mathrm{n} / \mathrm{a}$ \\
\hline $\begin{array}{l}\text { Slide the lever away until it } \\
\text { clicks }\end{array}$ & $\mathrm{n} / \mathrm{a}$ & 4.0 & $\mathrm{n} / \mathrm{a}$ \\
\hline $\begin{array}{l}\text { Twist the colored grip as far as } \\
\text { it will go. Then twist it all the } \\
\text { way back until it clicks }\end{array}$ & 0.0 & $\mathrm{n} / \mathrm{a}$ & 10.5 \\
\hline $\begin{array}{l}\text { Breathe out gently to residual } \\
\text { volume }\end{array}$ & 35.7 & 29.3 & 42.1 \\
\hline Close lips on inhaler & 0.0 & 0.0 & 0.0 \\
\hline Inhale slowly and deeply & 21.4 & $\mathrm{n} / \mathrm{a}$ & $\mathrm{n} / \mathrm{a}$ \\
\hline Inhale forcefully and deeply & $\mathrm{n} / \mathrm{a}$ & 25.3 & 21.1 \\
\hline $\begin{array}{l}\text { Hold breath for at least } 10 \\
\text { seconds }\end{array}$ & 21.4 & 17.3 & 10.5 \\
\hline $\begin{array}{l}\text { Patients performing incor- } \\
\text { rect inhalation techniques }\end{array}$ & 50.0 & 48.0 & 55.6 \\
\hline Odds ratio & 1.1 & 1.0 & 1.2 \\
\hline $95 \%$ confidence interval & $0.3-3.4$ & & $0.4-3.3$ \\
\hline$p$-value & 0.89 & & 0.72 \\
\hline
\end{tabular}

Abbreviations: pMDI, pressurized meter dose inhaler; $\mathrm{n} / \mathrm{a}$, not applicable to the device.

Table 3. Risk factors for incorrect inhalation techniques by univariable analysis $(\mathrm{n}=108)$

\begin{tabular}{|c|c|c|c|c|c|}
\hline Variables & & $\mathbf{n}$ & $\begin{array}{c}\text { Incorrect } \\
(\%)\end{array}$ & $\begin{array}{c}\text { Crude OR } \\
(95 \% \mathrm{CI})\end{array}$ & $p$-value \\
\hline \multirow[t]{2}{*}{ Sex } & Male & 38 & 52.6 & $1.2(0.5-2.7)$ & 0.59 \\
\hline & Female (Ref.) & 70 & 47.1 & & \\
\hline \multirow[t]{2}{*}{ Age } & $\geq 70 \mathrm{yrs}$ & 25 & 48.0 & $1.0(0.4-2.6)$ & 0.90 \\
\hline & $<70$ yrs (Ref.) & 83 & 49.4 & & \\
\hline \multirow[t]{2}{*}{ Education level } & Low ( $\leq 6$ years) & 29 & 58.6 & $1.7(0.7-4.0)$ & 0.23 \\
\hline & High (> 6 years) (Ref.) & 79 & 45.6 & & \\
\hline \multirow[t]{2}{*}{$\%$ predicted of $\mathrm{FEV}_{1}^{\mathrm{a}}$} & $<70$ & 37 & 54.1 & $1.4(0.6-3.2)$ & 0.42 \\
\hline & $\geq 70$ (Ref.) & 55 & 45.5 & & \\
\hline
\end{tabular}


Table 3. (Continued)

\begin{tabular}{|c|c|c|c|c|c|}
\hline Variables & & $\mathbf{n}$ & $\begin{array}{c}\text { Incorrect } \\
(\%)\end{array}$ & $\begin{array}{c}\text { Crude OR } \\
(95 \% \mathrm{CI})\end{array}$ & $p$-value \\
\hline \multirow[t]{2}{*}{ Ratio of $\mathrm{FEV}_{1} / \mathrm{FVC}(\%)^{\mathrm{a}}$} & $<70$ & 31 & 45.2 & $0.8(0.3-1.9)$ & 0.61 \\
\hline & $\geq 70$ (Ref.) & 61 & 50.8 & & \\
\hline \multirow[t]{2}{*}{ ACT score } & $<20$ & 25 & 52.0 & $1.2(0.5-2.8)$ & 0.74 \\
\hline & $\geq 20$ (Ref.) & 83 & 48.2 & & \\
\hline \multirow[t]{2}{*}{ History of AE in the previous year } & Yes & 29 & 44.8 & $0.8(0.3-1.8)$ & 0.59 \\
\hline & No (Ref.) & 79 & 50.6 & & \\
\hline \multirow[t]{2}{*}{ Treated by a pulmonologist for at least 2 years } & No & 39 & 64.1 & $2.6(1.1-5.9)$ & 0.02 \\
\hline & Yes (Ref.) & 69 & 40.6 & & \\
\hline
\end{tabular}

Notes: Data are $n(\%),{ }^{a} n=92$.

Abbreviations: OR, odds ratio; $\mathrm{FEV}_{1}$, forced expiratory volume in first second; ACT, Asthma control test; AE, acute exacerbation.

Univariable analysis of the determinants revealed only 2 potential risk factors for incorrect inhalation technique: low education level (education $\leq 6$ years) and previous treated by a pulmonologist for less than 2 years (Table 3 ). No significant associations could be made regarding sex, age, severity of disease defined by lung function, level of asthma control, and history of exacerbation. Multivariable logistic regression revealed that previous treatment by a pulmonologist for less than 2 years was the only associated factor for incorrect inhalation technique [adjusted $\mathrm{OR}=2.8(95 \% \mathrm{CI}, 1.2-6.3), \mathrm{p}=$ 0.02] (Table 4).

At their post-training visit, a total of $49.1 \%$ (53/108) of patients performed inhaler device demonstrations and their inhalation techniques were assessed again. Comparisons of incorrect techniques before and after face-to-face training visits are shown in Figure 1. Formal training resulted in a significant decrease in the percentage of incorrect techniques across all devices (52.8\% vs. $32.1 \%, p=0.02)$ and showed a tendency to decrease in the Turbuhaler ${ }^{\circledast}(75.0 \%$ vs. $25.0 \%, p=0.06)$.

The comparison of clinical control by means of ACT score between routine visit and one month after reinforcement of the correct use of controller devices was assessed in 53 asthma patients. These results are shown in Table 5. In the correct use of inhaler device group resulted in a significant increase in the mean ACT score (mean change $+1.76, p=0.04$ ). But this improvement in clinical control was not showed in the incorrect use of inhaler device group (mean ACT change $+0.60, p=0.25$ ).

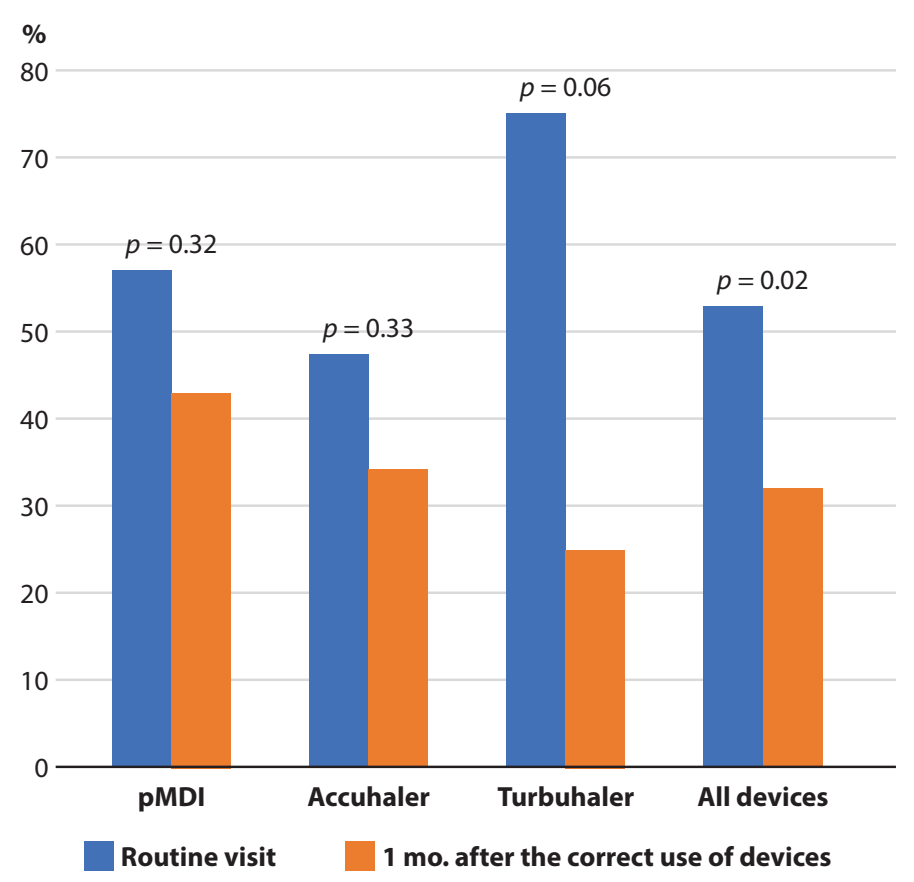

Figure 1. Comparison of use of incorrect techniques between routine visit and one month after reinforcement of the correct use of controller devices in $\mathbf{5 3}$ asthma patients.

Table 4. Risk factors for incorrect inhalation techniques by multivariable analysis $(\mathrm{n}=103)$

\begin{tabular}{|c|c|c|c|}
\hline \multicolumn{2}{|l|}{ Variables } & $\begin{array}{c}\text { Adjusted OR } \\
(95 \% \mathrm{CI})\end{array}$ & $p$-value \\
\hline \multirow[t]{2}{*}{ Treated by a pulmonologist for at least 2 years } & No & $2.8(1.2-6.3)$ & 0.02 \\
\hline & Yes (Ref.) & & \\
\hline \multirow[t]{2}{*}{ Education level } & Low ( $\leq 6$ years) & $1.8(0.8-4.6)$ & 0.17 \\
\hline & High (> 6 years) (Ref.) & & \\
\hline
\end{tabular}

Abbreviations: $\mathrm{OR}$, odds ratio; $\mathrm{CI}=$ confidence interval. 
Table 5. Comparison of clinical control by means of Asthma Control Test (ACT) score between routine visit and one month after reinforcement of the correct use of controller devices $(n=53)$

\begin{tabular}{lccc} 
& \multicolumn{3}{c}{ ACT score } \\
\cline { 2 - 4 } & Routine visit & 1 month after reinforcement & $p$-value \\
\hline Correct use at $\mathrm{F} / \mathrm{U}(\mathrm{n}=33)$ & $19.85 \pm 4.98$ & $21.61 \pm 3.57$ & 0.04 \\
\hline Incorrect use at $\mathrm{F} / \mathrm{U}(\mathrm{n}=20)$ & $22.35 \pm 2.20$ & $22.95 \pm 1.90$ & 0.25 \\
\hline
\end{tabular}

Abbreviations: ACT, Asthma control test.

\section{Discussion}

This study revealed that about half of asthma patients routinely treated by pulmonologists used their inhaler incorrectly by performing at least one of the essential steps for drug delivery incorrectly. The most errors were made by patients using the Turbuhaler, ${ }^{\circledast}$ whereas those patients using the Accuhaler $^{\oplus}$ had the highest rate of accuracy when it came to techniques, but there was no statistically significant difference. Previous studies, also reported that the Turbuhaler ${ }^{\circledast}$ had more technique errors than pMDI, and the Accuhaler ${ }^{\circledast 23,24} \mathrm{We}$ found that the rate of critical errors for dry powder inhaler (DPIs), Turbuhaler ${ }^{\circledast}$ and Accuhaler ${ }^{\circledast}$ was not significantly lower than that of pMDI which was similar to previous findings. ${ }^{23}$ Reported examples of the most common errors in all devices are no full exhalation to residual volume and no breath-holding.

Patient treatment by a pulmonologist for less than 2 years was the only associated factor for incorrectly performing inhalation techniques. A previous study also found that a longer duration of therapy was associated with a proper inhaler technique. ${ }^{25} \mathrm{~A}$ more recent study on asthma patients has identified that lack of regular follow-up was more likely to lead to improper use of inhaler device. ${ }^{26}$ Our study showed that many variables such as older age, female gender, severity of disease, low ACT score, history of exacerbation, and lower education level were not associated with incorrect technique. Similar to other studies, they found no significant correlation between socio-demographic data such as age, gender or education level and incorrect inhalation technique. ${ }^{27-29}$

This study used the ACT questionnaire and the data suggest that patients with a lower level of control of asthma (an ACT score $<20$ ) are not associated with incorrect inhalation technique. Furthermore, the association between poor clinical control and frequency of incorrect technique with inhalers in an observational study does not automatically mean that a better inhalation technique would necessarily improve clinical control. ${ }^{23}$ Several other factors may contribute to poor disease control, including patients with poor inhalation technique could also be non-adherent to drug prescriptions or lead uncorrected lifestyles. However, a previous study demonstrated that mishandling of inhaler technique remains common in real life and is associated with poor clinical control and an increased need for unscheduled health-care resources in COPD patients. ${ }^{23}$

Our study also confirms a significant increase in the percentage of inhalation technique improvement after face-toface demonstrations and training. Although the inhalation technique among patients significantly improved one month after the training, the percentage of those with incorrect technique was still above $30 \%$. Our results are in comparable to the recent systematic review demonstrating that the problem of device errors are common for over 40 years and this issue has still not been resolved. ${ }^{30}$ Several factors should be addressed e.g., standardized training of healthcare providers and patients for the different inhaler devices and regular re-evaluation of inhaler technique. ${ }^{31}$ The results of this study suggested that patients should bring all their inhalers to each visit, and should demonstrate their proper use to reinforce good practice and correct poor technique. All patients need face-toface training to help them recall training instructions for successful inhaler use. Inhaler technique must be rechecked and education must be reinforced regularly in order to maintain correct techniques, as inhaler technique deteriorates again after re-education. ${ }^{2,16,32,33}$ Handouts and/or videos are not a substitute for face-to-face training and, as previously mentioned, the trainer must be aware of the patient's learning needs. ${ }^{34}$ The basics of effective inhaler training and consequently effective treatment are: simplification, demonstration, and repetition. ${ }^{34}$ Regular reassessment and reinforcement of correct inhalation techniques are essential for successful inhaler use.

This study has some strength. Firstly, our study represents a reliable approach to real-world clinical practice. Bias was mitigated when asthma patients were assessed without prior notification of the study or researcher knowledge of their inhaler education at their routine visit. Secondly, the same nurse evaluated the same patient for both pre-training and post training visits to avoid inter-observer variability. However, this study had some limitations. Firstly, this study was conducted in a single institution and we cannot exclude selection bias. This may limit the generalization of our results to other populations. As our center is an academic center, the inhalation techniques of common inhaler devices were still largely unsatisfactory. It might be postulated that the inhalation technique of asthma patients in general practice clinics without face-toface training will be more unsatisfactory. Secondly, we recognized that evaluating some steps, especially the step involving rapid and forceful inhalation which is needed to correctly use a dry powder inhaler, only through observation is subjective. However it does simulate a real life setting, where most decisions are clinically based and the equipment to accurately measure the inspiratory flow is seldom available. However, the true value of this work can be seen in the improvement in inhaler use after face-to-face training confirming the need for repeated education, not only on the comparison of inhalation techniques between devices. Thirdly, this study evaluated 
inhalation technique without a quality grading. This method may overestimate the prevalence of incorrect use of inhaler devices, since it considered all steps recommended by manufacturers as a potential source of error. It does reduce the subjectivity of grading the relevance of some errors over others in the absence of solid knowledge on the importance of each error on the distribution of the drug into the airways. Fourthly, the spirometry was not assessed in all routine visits at our center. Therefore, the comparison of lung function by $\mathrm{FEV}_{1}$, $\mathrm{FVC}$, and $\mathrm{FEV}_{1} / \mathrm{FVC}$ between routine visit and one month after training of the correct use of controller devices was not addressed. Fifthly, the effect of changes to different devices and rate of incorrect inhalation technique was not mentioned in this study. Future studies need to focus on the association between changes in different inhaler devices used and frequency of incorrect technique.

In conclusion, inhalation technique in asthma patients without face-to-face training was found to be mostly unsatisfactory, especially in patients treated by a pulmonologist for less than 2 years. The Accuhaler ${ }^{\circledast}$ was the inhaler device associated with the lowest technique failure. Face-to-face inhalation technique training significantly increased technique compliance in the use of all devices.

\section{Acknowledgments}

The authors wish to thank the patients who participated in this study and to acknowledge the staff members of the Division of Pulmonary, Critical Care and Allergy, Department of Internal Medicine, Faculty of Medicine, Chiang Mai University for their contribution to this trial.

\section{Author contributions}

The first author developed study design and carried out acquisition and interpretation of data, statistical analysis, manuscript preparation, and critical revision of intellectual contents. The other authors conducted acquisition and interpretation of data and critical reviews of the manuscript. All authors read and approved the final manuscript.

\section{Conflict of interest}

The authors have no potential conflict of interest.

\section{References}

1. Arora P, Kumar L, Vohra V, Sarin R, Jaiswal A, Puri MM, et al. Evaluating the technique of using inhalation device in COPD and bronchial asthma patients. Respir Med. 2014;108(7):992-8.

2. Wright J, Brocklebank D, Ram F. Inhaler devices for the treatment of asthma and chronic obstructive airways disease (COPD). Qual Saf Health Care. 2002;11(4):376-82.

3. Boonsawat W, Thompson PJ, Zaeoui U, Samosorn C, Acar G, Faruqi R, et al. Survey of asthma management in Thailand - the asthma insight and management study. Asian Pac J Allergy Immunol. 2015;33(1):14-20.

4. Virchow JC. What plays a role in the choice of inhaler device for asthma therapy? Curr Med Res Opin. 2005;21(Suppl 4):S19-25.

5. Virchow JC, Crompton GK, Dal Negro R, Pedersen S, Magnan A, Seidenberg J, et al. Importance of inhaler devices in the management of airway disease. Respir Med. 2008;102(1):10-9.

6. Dolovich MB, Ahrens RC, Hess DR, Anderson P, Dhand R, Rau JL, et al. Device selection and outcomes of aerosol therapy: Evidence-based guidelines: American College of Chest Physicians/American College of Asthma, Allergy, and Immunology. Chest. 2005;127(1):335-71.
7. Cochrane MG, Bala MV, Downs KE, Mauskopf J, Ben-Joseph RH. Inhaled corticosteroids for asthma therapy: patient compliance, devices, and inhalation technique. Chest. 2000;117(2):542-50.

8. Global Initiative for Asthma. Global Strategy for Asthma Management and Prevention [Internet]. [Bethesda]: Global Initiative for Asthma; c2016 [cited 2015 Aug 11]. Available from: http://www.ginasthma.org

9. Chorao P, Pereira AM, Fonseca JA. Inhaler devices in asthma and COPD--an assessment of inhaler technique and patient preferences. Respir Med. 2014;108(7):968-75.

10. Ganguly A, Das AK, Roy A, Adhikari A, Banerjee J, Sen S. Study of Proper use of Inhalational Devices by Bronchial Asthma or COPD Patients Attending a Tertiary Care Hospital. J Clin Diagn Res. 2014;8(10):HC04-7.

11. Brocklebank D, Ram F, Wright J, Barry P, Cates C, Davies L, et al. Comparison of the effectiveness of inhaler devices in asthma and chronic obstructive airways disease: a systematic review of the literature. Health Technol Assess. 2001;5(26):1-149.

12. Rootmensen GN, van Keimpema AR, Jansen HM, de Haan RJ. Predictors of incorrect inhalation technique in patients with asthma or COPD: a study using a validated videotaped scoring method. J Aerosol Med Pulm Drug Deliv. 2010; 23(5):323-8.

13. van Beerendonk I, Mesters I, Mudde AN, Tan TD. Assessment of the inhalation technique in outpatients with asthma or chronic obstructive pulmonary disease using a metered-dose inhaler or dry powder device. J Asthma. 1998;35(3):273-9.

14. Harvey J, Williams JG. Randomised cross-over comparison of five inhaler systems for bronchodilator therapy. Br J Clin Pract. 1992;46(4):249-51.

15. Deerojanawong J, Promsaka na Sakolnakorn V, Prapphal N, Hanrutakorn C, Sritippayawan S. Evaluation of metered-dose inhaler administration technique among asthmatic children and their caregivers in Thailand. Asian Pac J Allergy Immunol. 2009;27(2-3):87-93.

16. Pothirat C, Chaiwong W, Phetsuk N, Pisalthanapuna S, Chetsadaphan N, Choomuang W. Evaluating inhaler use technique in COPD patients. Int J Chron Obstruct Pulmon Dis. 2015;10:1291-8.

17. Miller MR, Hankinson J, Brusasco V, Burgos F, Casaburi R, Coates A, et al. Standardisation of spirometry. Eur Respir J. 2005;26(2):319-38.

18. Nathan RA, Sorkness CA, Kosinski M, Schatz M, Li JT, Marcus P, et al Development of the asthma control test: a survey for assessing asthma control. J Allergy Clin Immunol. 2004;113:59-65.

19. Reddel HK, Taylor DR, Bateman ED, Boulet LP, Boushey HA, Busse WW, et al. An official American Thoracic Society/European Respiratory Society statement: asthma control and exacerbations: standardizing endpoints for clinical asthma trials and clinical practice. Am J Respir Crit Care Med. 2009;180(1):59-99.

20. Pellegrino R, Viegi G, Brusasco V, Crapo RO, Burgos F, Casaburi R, et al. Interpretative strategies for lung function tests. Eur Respir J. 2005;26(5): 948-68.

21. Thomas M, Kay S, Pike J, Williams A, Rosenzweig JR, Hillyer EV, et al. The Asthma Control Test (ACT) as a predictor of GINA guideline-defined asthma control: analysis of a multinational cross-sectional survey. Prim Care Respir J. 2009;18:41-9.

22. Hosmer DLS. Applied Logistic Regression. 2nd ed. New York, USA: John Wiley \& Sons; 2000.

23. Melani AS, Bonavia M, Cilenti V, Cinti C, Lodi M, Martucci P, et al. Inhaler mishandling remains common in real life and is associated with reduced disease control. Respir Med. 2011;105(6):930-8.

24. Molimard M, Raherison C, Lignot S, Depont F, Abouelfath A, Moore N. Assessment of handling of inhaler devices in real life: an observational study in 3811 patients in primary care. J Aerosol Med. 2003;16(3):249-54.

25. Elif Şen UG, Zuhal Ekici, Nazmiye Kurşun. Assessment of inhaler technique and treatment compliance of hospitalized patients and outpatients in a university hospital. J Ankara Univ Fac Med. 2006;59:1-6.

26. Al-Jahdali H, Ahmed A, Al-Harbi A, Khan M, Baharoon S, Bin Salih S, et al. Improper inhaler technique is associated with poor asthma control and frequent emergency department visits. Allergy Asthma Clin Immunol. 2013;9(1):8.

27. Shrestha M, Parupia H, Andrews B, Kim SW, Martin MS, Park DI, et al. Metered-dose inhaler technique of patients in an urban ED: prevalence of incorrect technique and attempt at education. Am J Emerg Med. 1996;14(4):380-4

28. Golpe Gomez R, Mateos Colino A, Soto Franco I. Inadequate technique in the use of inhalers in patients seen at a pneumology clinic. An Med Interna. 2001;18(2):69-73. 


\section{APJAI}

29. Gray SL, Williams DM, Pulliam CC, Sirgo MA, Bishop AL, Donohue JF. Characteristics predicting incorrect metered-dose inhaler technique in older subjects. Arch Intern Med.1996;156(9):984-8.

30. Sanchis J, Gich I. Pedersen S. Aerosol drug management improvement team (ADMIT). Systematic review of errors in inhaler use: has patient technique improved over time? Chest. 2016;150,394-406.

31. Chrystyn H, van der Palen J, Sharma R, Barnes N, Delafont B, Mahajan A, et al. Device errors in asthma and COPD: systematic literature review and meta-analysis. NPJ Prim Care Respir Med. 2017;27(1):22.

32. Steier J, Trammer T, Cloes RM, Petro W. Optical feedback training of inhalation with Autohaler and Turbuhaler in COPD patients. Lung. 2003;181(4):183-92.
33. Crompton GK, Barnes PJ, Broeders M, Corrigan C, Corbetta L, Dekhuijzen $\mathrm{R}$, et al. The need to improve inhalation technique in Europe: a report from the Aerosol Drug Management Improvement Team. Respir Med. 2006;100(9):1479-94.

34. Broeders ME, Sanchis J, Levy ML, Crompton GK, Dekhuijzen PN, Group AW. The ADMIT series--issues in inhalation therapy. 2. Improving technique and clinical effectiveness. Prim Care Respir J. 2009;18(2):76-82. 